\title{
CONCEPT ON SINGLE ACTUATING BRAKING SYSTEM FOR TWO WHEELER
}

\author{
Parsuram sah turaha1, M.K. Pradhan² \\ Dept. of Mechanical Engineering, Maulana Azad National Institute of Technology, Bhopal,India \\ Email: ${ }^{1}$ arsuramsah@gmail.com, ${ }^{2}$ mohanrkl@gmail.com
}

\begin{abstract}
An attempt has been made to solve the braking problem during hard braking. In case of motor bike, It has been seen that when the driver has to stop the motorbike immediately, he becomes confused which brake should applied and then he uses either front brake or rear brake or both brake and due to this an unbalanced is occur between the wheel and caused the accident. To solve this problem a single actuating braking system can be used. In this braking system, the front and rear hydraulic brake are operated by only single actuating system that is the brake pedal assembly. The purpose of the single actuating braking system is for the locking of both front and rear wheel at the same time without slipping and skidding. Since both the brake front and rear are operated by the tandem master cylinder, the pressure to the both calipers will be equal, so the both wheels can be locked and stop at the same time. The design of this braking system increases the simplicity of the actuating system. Since this braking system has only one actuating system, the overall cost is reduced. A tandem master cylinder can be used since it has two outlet valve primary and secondary which will be used for front and rear brake caliper respectively. Also the braking force, braking distance and time will be calculated during braking.
\end{abstract}

Key words: single actuating system, braking force, braking distance and braking time.

\section{INTRODUCTION}

In the aspect of the two wheeler accident prevention, the braking performance of vehicles has been considered as a critical issue. The driving safety and braking performance is very important matter for the human life. A safe braking system must have to prevent these problems. Skidding and slipping are the most important factor in the braking system. These factors cause the unbalance between the wheels of the vehicle resulting accident. For this purpose a single actuating braking system is trying to use for solving this problem. This system uses tandem master cylinder as a double master cylinder. Braking system will have two independent hydraulic circuits such that in the case of a leak or failure at any point in one of the hydraulic circuits, in the system, sufficiently effective braking power is maintained on at least one wheel. The brake system consists of two wheel disc brakes actuated by a tandem master cylinder. A tandem master cylinder is used to meet the requirement of having two independent front and rear brake circuits. We chose this setup over a tandem master cylinder because it is easier to install and adjustable. This system will allow the vehicle to maintain braking power in the case of a leak or failure in any of the circuit. It has two out let valve primary and secondary which linked with the front and rear caliper. When the brake pedal is pressed the brake fluid applied the pressure to the caliper and brake will be applied. This will result same pressure to both the caliper and stopping of both the wheel at the same time. This system is verified by calculating braking force, braking distance, and braking time.
Here, the braking distance indicates the total distance travelled by a vehicle starting from certain speed to stop, and it can be estimated by traditional experimental method. This implies that the vehicle components which affect the braking performance should be appropriately designed so as to meet the safe braking parameter. This paper helps to calculate the braking parameter of a vehicle equipped with the single actuating braking system.

\section{LITERATURE REVIEW}

A single actuating braking system will be able to solve so many problems which results accident in two wheelers. There are so many accidents happen due to the unbalanced braking system. One indicator of the under consideration of two wheeler by the transport system is the high level of risk they are faced with. Two wheeler riders are among the road users who are most vulnerable to road risks, along with pedestrians and cyclists (1). Statistical data show that they account for more than $16 \%$ of people killed in India on roads each year. In OECD countries more generally, more than 11,000 TW riders are killed on the roads each year, accounting on average for $14 \%$ of total fatalities, while TWs account for around $5 \%$ of the fleet and even less if mileage is considered (2). The share of TW fatalities can be much higher in low and middle income countries, with nearly 200,000 deaths worldwide, according to the World Health Organization (1). Moreover, medical data suggest a dramatic amount of severe injuries among this population compared to their moderate share in the overall traffic. Thus, it is recognized that TW fatality and injury rates 
are worse than for car occupants, with figures varying depending on the countries considered. Moreover, whereas an overall tendency toward an improvement in traffic safety for passenger cars has been noted for most countries around the world, both for fatalities and injuries (2), TWs do not follow this trend: as indicated by Shinar (2012), progress has not been as consistent for vulnerable road users as a whole and specifically for TW riders. According to Haworth (3), motorcycling tends to be little safer, general progress in fatality rates can be seen, with some exceptions, partly in connection with the number of returning riders and weakened mandatory helmet laws in many states. There is also a little decrease in the number of seriously injured road users in nearly all OECD countries(2), although this reduction is less marked than for fatalities. But this progress is not as substantial as the light of the far greater progress in overall road safety made during the same period in the same regions, the result being an excess risk for TW riders per mile ridden as compared to car drivers. All these results show that, as indicated above, the problems are not so simple. And by simplifying them too much, we risk missing the complementarities between the different levers of action. We need to understand the stakes of the core parameters involved both on the primary safety level (the causes of crashes) and on the secondary safety level (the causes of injuries and fatalities) so that we can adequately define preventive and protective countermeasures. To prevent from these problems, some paper has been published. Elsevier, (4)powered two wheelers within the traffic system. This paper only talked about the traffic and road condition problem. Biswarup Das and Arindam Ghosh, (5) A novel control strategy for a braking resistor. This tells about the electronic control braking system. Hossein Mirzaeinejad and Mehdi Mirzaei, (6) (2014) Optimization of nonlinear control strategy for anti-lock braking system with improvement of vehicle directional stability on split roads. This braking system improves only the directional stability of the vehicle. Beibei Jiaa and Guangquan Lu, (7)The Measurement for Performance Parameter of Automobile Braking System with Electronic Vacuum Booster. This system measures only the performance parameters. Federico Giovannini and Giovanni Savino, (8) Analysis of the minimum swerving distance for the development of a motorcycle autonomous braking system. This paper focused only on the swirling distance. Jakkam Surender, (9) Pattern of Injuries in Fatal Road Traffic Accidents in Warangal Area.

There are so many papers which have been published to solve the accident problem during braking. Some of them are mentioned above. All of these are tries to solve by their won way, but they have not discussed about the single actuating braking system which can also be favourable for a better solution. They have not been explained about the main causes of the accident during braking. So the single actuating braking system has explained both the causes and solution of the accident during braking.

\section{III.BRAKING SYSTEM PARAMETERS}

The braking system is controlled by a fully hydraulic independent circuit with tandem master cylinder. The braking parameters of the system are those which affect the performance and stability of the vehicle and these can be determined by the analytical method using the following relationship.

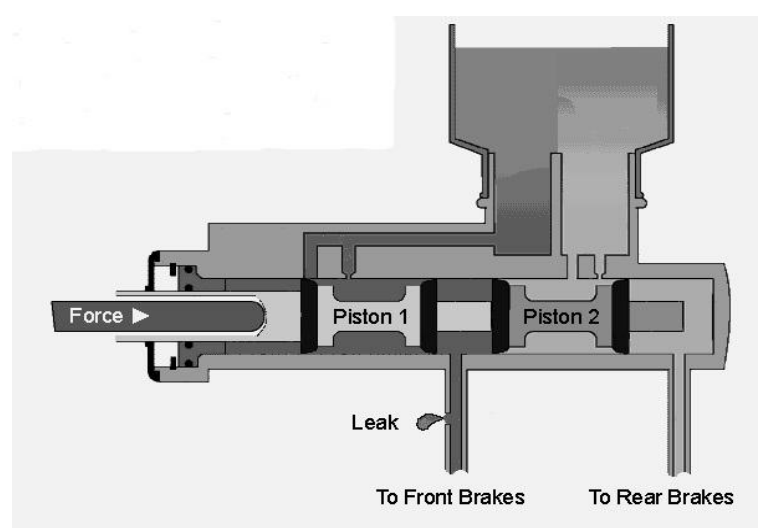

Figure1: Tandem master cylinder Weight

$$
\begin{array}{r}
\text { Distribution While Braking: } \\
\mathrm{R}_{\mathrm{F}}=\{(1+\mu h) \cos \theta \div \mathrm{b}\} W \ldots \ldots \ldots \ldots \text { (i) } \\
\mathrm{R}_{\mathrm{R}}=\{(b-\mid-\mu h) \cos \theta \div \mathrm{b}\} W \ldots \ldots \text { (ii) }
\end{array}
$$

In case the vehicle moves on a level road, $\theta=0$ and hence in the above expressions the values of $\sin \theta=0$ and $\cos \theta=1$.

When the vehicle moves up a gradient only the sign of $\sin \theta$ alters, changing the value of $f / g$. The expansions for $R_{R}$ and $R_{F}$ remain unaffected.

$\theta=$ Angle of inclination of the plane with horizontal $=0^{\circ}$

$\mathrm{W}=$ Weight of vehicle $=\mathrm{mg}$

$R_{F}, R_{R}=$ Reactions of the ground on the front and rear wheels respectively.

$f=$ Retardation of the vehicle.

$\mathrm{f}_{\mathrm{T}}=$ Retardation at which vehicle can topple.

$b=$ Wheel base of the vehicle.

$h=$ Height of the center of mass of the vehicle from the inclined surface.

I = Distance of the center of mass from the rear axle.

$\mu=$ Coefficient of friction between the ground and the tires.

$\mathbf{s}=$ Stopping distance.

$\mathrm{t}=$ Stopping time.

$r=$ radius of friction pad. 
Then,

Retardation,

$f=\mu g$

Stopping Distance,

$\mathrm{s}=\mathrm{v}^{2} / 2 \mu \mathrm{g}$

Stopping time,

$\mathrm{t}=\mathrm{v} / \mathrm{f}$

Torque on a single wheel, when skidding will start

$$
T=\left(\mu{ }^{*}{ }^{*} R\right) / 2
$$

If $F$ is the braking force, then,

$\mathrm{F}=$ pedal force * pedal ratio

The Braking torque formed on the rotor,

$$
\mathrm{B}_{\mathrm{T}}=2 \mathrm{~F}^{*} \mu_{1}{ }^{*} \mathrm{r}
$$

Note: $\mathrm{B}_{\top} \geq \mathrm{T}$

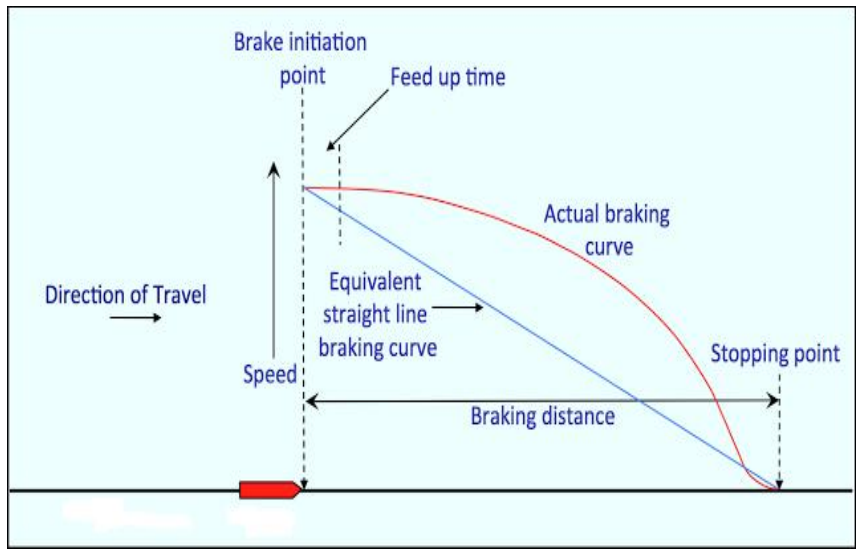

\section{Figure 2: The relationship between braking distance and speed.}

The above figure shows the actual braking curve and equivalent straight line braking curve formed between the braking distance and speed of the vehicle. The path, follow by the actual curve is always different than the theoretical curve due to the driver reaction time as well as the some mechanical losses in the braking system mechanism.

Table 1. The different distance during braking

\begin{tabular}{|c|c|c|c|}
\hline Speed $(\mathrm{km} / \mathrm{ph})$ & $\begin{array}{c}\text { Thinking } \\
\text { distance }(\mathrm{m})\end{array}$ & $\begin{array}{c}\text { Braking } \\
\text { distance }(\mathrm{m})\end{array}$ & $\begin{array}{c}\text { Stopping } \\
\text { distance }(\mathrm{m})\end{array}$ \\
\hline 20 & 1 & 2 & 3 \\
\hline 30 & 4 & 5 & 9 \\
\hline 40 & 7 & 8 & 15 \\
\hline 50 & 10 & 12 & 22 \\
\hline 60 & 13 & 18 & 31 \\
\hline 70 & 16 & 24 & 40 \\
\hline
\end{tabular}

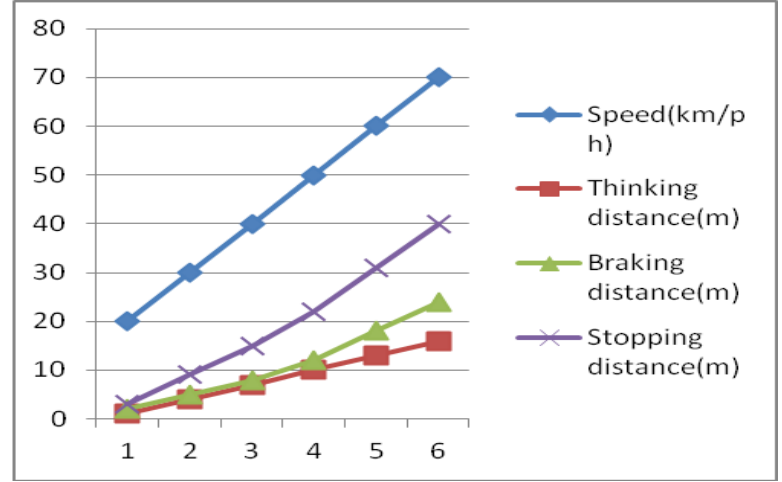

\section{Chart 1:The curve of different distances during the braking.}

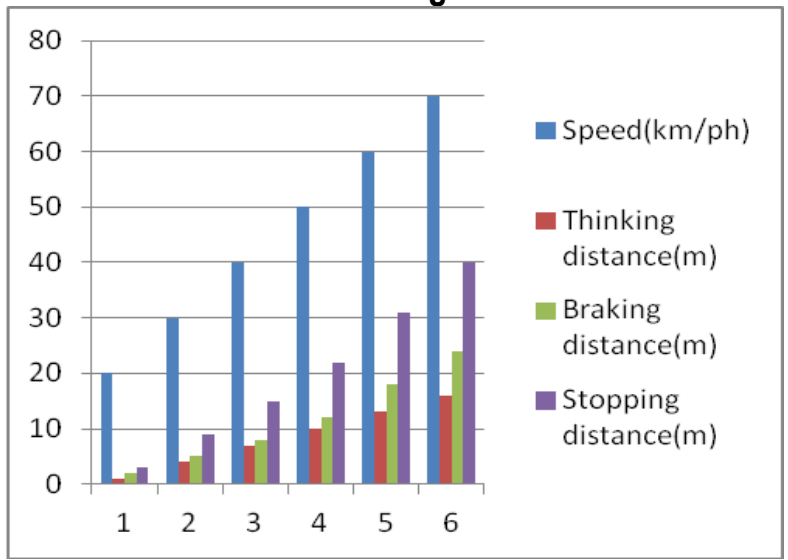

Chart2: Braking distances at different velocity.

The above charts show how, under normal driving conditions, thinking distance and braking distance depend on the speed of the vehicle.

Thinking distance - The time take by driver to react according to a situation. During this reaction time the vehicle keeps on moving. The thinking distance is the distance travelled in between the driver realizing he needs to brake and actually braking.

Stopping distance $=$ Thinking distance + Braking distance .

Braking distance - The braking distance is the distance taken by the vehicle to stop when the brakes are applied. The main cause of increasing the thinking distance are greater speed, tiredness, alcohol and drugs, distractions etc and for the braking distance are greater speed, poor road conditions, vehicle conditions like poor brakes.

\section{DISCUSSION}

In this paper, the single actuating control system of the brake is actuated by hydraulic pressure during a braking process. This system has been designed and developed to meet the basic design criteria of the braking system. This 
proposed system can be offered advanced abilities in the dynamic directional control of the vehicle. The key advance of the braking system is that the current and previous system has been taken into consideration. This system can be taken as a sensitive braking system. The brake pressure is able to provide the desired brake pressure in different braking situations. It can significantly increase the two wheeler safety, to provide shorter braking distance and better braking force distribution between the two wheels. The torque on the wheel can be determined and then the torque required to stop vehicle can determined by considering the parameters of the brake assembly. Then the pedal ratio can be fixed to get the desired braking force from the driver. This system will be more economical than the other electronic braking system like ABS. The proposed single actuating braking system can be implemented experimentally verified using low cost.

\section{V.CONCLUSIONS}

During a hard braking on a road, achievement of shorter stopping distance and preventing the vehicle from slipping, skidding and deviation from the straight line is very important. From the above discussion single actuating braking system can be used for proper distribution of braking force on both the wheel of the vehicle. On the basis of this actuating system maximum braking torque can be produced to stop the vehicle on two wheels. The possibility of accidents can be minimized, so this system can optimize the control between the stopping distance and deviation from the straight line due to slipping and skidding.

\section{ACKNOWLEDGEMENT}

I would like to gratefully and sincerely thank $\mathrm{Dr}$. M. K. Pradhan, Department of Mechanical Engineering, MANIT, BHOPAL for his valuable guidance, suggestions and most importantly, making this project successful during my graduate studies at MANIT, BHOPAL.

\section{REFERENCES}

[1] World Health Organisation. Road Traffic Injuries Fact, March 2013. Available from: http://www.who.int/mediacentre/factsheets/fs358/en/ [Last accessed on $2013 \mathrm{Jul}]$
[2] The international road traffic and accident database of the international transport forum annualreport2013.http://www.nrso.ntua.gr/index.php/knowled ge/item/548-irtad-road-safety-annual-report-2013.html

[3] Rowden, P. J., Watson, B. C., \& Haworth, N. L. (2012). Risk taking by motorcyclists: rider training and stages of change. In Australasian Road Safety Research, Policing and Education Conference 2012, 4-6 October 2012, Wellington, New Zealand.

[4] Van Elslande, P., \& Elvik, R. (2012). Powered two-wheelers within the traffic system. Accident Analysis \& Prevention, 49, $1-4$.

[5] Das, B., \& Ghosh, A. (1998). A novel control strategy for a braking resistor.International Journal of Electrical Power \& Energy Systems, 20(6), 391-403..

[6] Mirzaeinejad, H., \& Mirzaei, M. (2014). Optimization of nonlinear control strategy for anti-lock braking system with improvement of vehicle directional stability on $s p l i t-\mu$ roads. Transportation Research Part C: Emerging Technologies, 46, 1-15.

[7] Jia, B., Lu, G., Wang, Y., \& Yu, G. (2013). The Measurement for Performance Parameter of Automobile Braking System with Electronic Vacuum Booster. Procedia-Social and Behavioral Sciences, 96, 2058-2065

[8] Giovannini, F., Savino, G., Pierini, M., \& Baldanzini, N. (2013). Analysis of the minimum swerving distance for the development of a motorcycle autonomous braking system. Accident Analysis \& Prevention, 59, 170-184.

[9] Surender, J. (2013). Pattern of Injuries in Fatal Road Traffic Accidents in Warangal Area. Journal of Indian Academy of Forensic Medicine, 35(1), 55-59.

[10] Aleksendrić, D., Jakovljević, Ž., \& Ćirović, V. (2012). Intelligent control of braking process. Expert Systems with Applications, 39(14), 11758-11765.

[11] Puhn, F. (1985). Brake handbook. HP Books.

[12] Gupta R.B, 200, Automobile engineering seventh edition, Tech India publication, India.

[13] Heisler, H. (2002). Advanced vehicle technology. Elsevier.

[14] Stone, R., \& Ball, J. K. (2004). Automotive engineering fundamentals (Vol. 199). SAE Technical Paper. 